\title{
An Improved Swarm Intelligence Algorithm for Multi-Item Joint Ordering Strategy of Cruise Ship Supply
}

\author{
Liling Huang $(\mathbb{D}$ and Jiaqi Yang \\ School of Transportation, Wuhan University of Technology, Wuhan 430064, China \\ Correspondence should be addressed to Liling Huang; 316536524@qq.com
}

Received 7 December 2019; Revised 8 February 2020; Accepted 21 February 2020; Published 14 March 2020

Guest Editor: Chi-Hua Chen

Copyright (c) 2020 Liling Huang and Jiaqi Yang. This is an open access article distributed under the Creative Commons Attribution License, which permits unrestricted use, distribution, and reproduction in any medium, provided the original work is properly cited.

\begin{abstract}
From the perspective of the global value chain of the cruise industry, the output value of cruise operation accounts for $50 \%$, with the highest added value, and cruise ship supply is the crucial link in cruise operation management, with substantial economic benefits. Therefore, optimizing the purchasing process can not only save costs for cruise companies but also improve cruise level service. Aiming at the purchasing characteristics and modes of cruise ship supply, an optimization model of multi-item joint ordering is constructed under global cruise ship supply chain, considering different order cycles, integrated operation of purchase, delivery, and inventory based on a cruise distribution center. And an improved swarm intelligence algorithm, called fireworks algorithm with inertia weight (WFWA), is proposed for global optimization of the objective function. By comparing the optimization results with fireworks algorithm (FWA), genetic algorithm (GA), and particle swarm optimization (PSO) through experimental tests, it demonstrates that WFWA has higher optimization accuracy and better global convergence.
\end{abstract}

\section{Introduction}

In recent years, the cruise industry has developed from a narrow cruise reception economy to a broad cruise industry chain, further providing policy innovation for the development of related industries such as cruise supply chain, cruise ship supply, and supporting facilities of cruise home port. In the cruise industry chain, a large part is the cruise ship supply, which is the main component of the cruise operation management and accounts for $50 \%$ of the output value, with the highest added value. At the same time, it is also an essential part of the cruise industry chain, an important indicator to measure the competitiveness of a cruise home port, and one of the key elements to attract international cruise ships to come to ports for regular operation. Although the number of cruise ports tourists is increasing year by year in China, few of them are profitable, and the profit point is concentrated in the procurement and logistics business of cooperative enterprises, without giving full play to the added value of the tourism industry. Therefore, the operation of cruise ships directly affects the economic benefits of cruise companies and plays a vital role in the economy of cruise home port.

The cruise ship is a special kind of vessel for international navigation. In the broad sense, cruise ship supplies are basically the same as ship materials, which can divided into fuel, materials, consumables, and duty-free goods. In the narrow sense, cruise materials refer to the food and daily necessities used and consumed by cruise service personnel and passengers during the voyage. For example, a cruise ship carrying 2700 passengers, which has a one-week journey (7 days and 6 nights), needs to prepare supplies including 12,000 liters of soda water, 4500 kilograms of chicken, 71,000 eggs, 2500 kilograms of bacon, 3500 liters of ice cream, 20,000 bottles of drinking water, and 10,000 bottles of liquor and beverages. Therefore, the replenishment of cruise ship supplies is enormous. Furthermore, with the large-scale development of cruise ships, ship tonnage and passenger capacity gradually increase, which bring many challenges to cruise ship operation management [1]. Therefore, the ordering of cruise ship supply needs to make full use of the advantages of globalization to achieve cost reduction. Cruise 
companies should focus on solving and ensuring the uninterrupted cruise ship supply during the voyage. Moreover, the multi-item joint ordering plays a role in cruise supply chain management and coordination, and the cruise distribution center is an important part of the cruise ship supply logistics system as the final hub of ship supplies.

Compared with the supply of ordinary cargo ships, the purchase of cruise ship supplies has the following characteristics:

(1) Global procurement: compared with ordinary cargo ships, cruise ships carry a large number of passengers. For example, there are more than 8000 people in the Quantum of the Seas which needs a large number of living materials and other spare parts. To ensure quality and reduce procurement cost, cruise ship supplies require global sourcing.

(2) High frequency replenishment: cruise ships usually have a period of several days or weeks to realize the cycle of departure and return. Compared with freighters, materials are consumed quickly and there is a need for replenishment in a short time. Besides, cruise ship needs consumable replenishment when it arrives at an intermediate location every time.

(3) The cruise company purchases directly from suppliers, while the cargo ships purchase from agent companies.

(4) A centralized hub is needed to check the quality and safety of the supplies, which ensures that supplies arrive at the cruise ships within the expected time.

The remainder of the paper is as follows. In Section 2, a relevant literature review is provided. In Section 3, the problem is formally discussed and an optimization model is formulated. Later, Section 4 proposes an improved swarm intelligence algorithm to solve the optimization problem. Afterward, the results and analysis are presented compared with other three swarm intelligence algorithms through a case study in Section 5. Eventually, Section 6 concludes this article and suggests possible research directions in the future.

\section{Literature Review}

2.1. Cruise Ship Supply. Jones [2] pointed out that ship replenishment materials provided by ship suppliers mainly include dry goods, food, cabin supplies, deck supplies, tools supplies, bonded materials, and oil materials. Véronneau and Roy [3] analyzed the planning process of the cruise supply chain and proposed that the cruise operation focuses on logistics supply. Véronneau and Roy [3] and Vaggelas and Lagoudis [4] considered that the global cruise supply chain faced the challenge of supply point mobility, and the replenishment ports were always under dynamic change. Moreover, with the distance between the port of call and the raw material supply point farther away, the purchase lead time further increased. According to Boyd tactical cycle theory, Véronneau and Cimon [5] proposed that the purchase lead time should be shorter than cruise length to remain the responsive within a certain period, and shortening the delivery time was the primary solution to provide more flexibility and further shift to a pull supply system. Lois et al. [6] considered that a holistic and systematic approach was necessary to ensure the safety and security of the cruise ship, so cruise ship supply needed to flow through a centralized distribution center to check quality and safety and ensure that supplies arrive onboard as expected. Compared with the rapid development of cruise tourism in China, the research on cruise ship supply is relatively lagging, and most of them are macroscopic. For example, Fu and Shou [7] and Liu [8] proposed that cruise ship supply chain was complex, global, time-sensitive, irreversible, and subject to supply variability. Yin [9] studied the distribution problem of cruise ship supply, which had the characteristics of large quantity, high value, and strict time requirement and required specialized cruise distribution centers and supporting facilities to centralized procurement, centralized supervision, centralized distribution, and centralized settlement for the distribution development. Zheng et al. [10] studied the fuel consumption of a voyage for cruise ships.

Based on the above analysis, more and more scholars pay attention to the replenishment of cruise ship supply. Because each material has different order cycle in multisourcing mode for cruise ship supply, a minimal cost model of cruise ship supply logistics is established from the perspective of cruise ship supply chain management, combined with the characteristics and purchasing mode of cruise ship supply logistics, considering purchase price, order cycle, inventory capacity, etc. In the existing studies, few of them have attempted to solve a similar problem.

2.2. Joint Ordering. Balintfy [11] was the first to propose the $(\mathrm{S}, \mathrm{c}, \mathrm{S})$ strategy, marking the beginning of the research on multi-item joint ordering; this system was a particular continuous inventory system used to coordinate the order of goods. Goyal [12] and Sivler [13] studied the multi-item material inventory model without considering the constraints of capital, resources, and inventory capacity, assuming that the demand rate was constant, the order price was fixed, and there was no shortage. Pirkul and Aras [14] proposed a multiproduct inventory model considering constraints of single resource capital, warehouse volume, and service level. Domestic scholars focused on the uniform ordering strategy and joint ordering strategy with fixed cycle. For example, $\mathrm{Xu}$ and $\mathrm{Xu}$ [15] studied the method of joint ordering in batches and fixed a minimum order cycle as the basic order cycle; others are integer times of the basic order cycle, and the ordering quantity was determined by respective demand rate, recovery rate, repair rate, and order cycle. Zhu et al. [16] analyzed the advantages, disadvantages, and conditions of the aggregation effect for three strategies: individual ordering, joint ordering, and unified ordering for multi-item or multiple customer ordering strategy in the supply chain. Wen and Da [17] established a multi-item inventory model for a deteriorated product supply chain and analyzed the properties of the total cost function based on 
five different ordering strategies. Besides, in the research of multi-item joint ordering optimization method with stochastic demand, Zhang et al. [18] discussed the joint ordering inventory problem based on random continuous inventory strategy considering service level constraints, and a heuristic algorithm for key decision parameters was proposed for the multi-item joint ordering problem. Zhang et al. [19] built a multi-item joint ordering model based on fixed-period strategy under the condition of stochastic demand, taking into account the constraints of guarantee degree, using the Monte Carlo stochastic simulation technology to solve the expected value of random variables, and genetic algorithm was used to calculate the minimum inventory cost of the basic order cycle, order cycle of each product, and the maximum inventory. Guan and $\mathrm{Wu}$ [20] established a fuzzy multiobjective mixed-integer programming model of single-stage and multi-item ordering quota allocation with fuzzy demand and price discount, and the two-stage algorithm was applied to solve it.

At present, the research on joint ordering problem and algorithms has made great achievement [21-26]; most of them adopt heuristic algorithms to solve it, such as genetic algorithm (GA), particle swarm optimization (PSO), differential evolution algorithm (DE), and improved or hybrid algorithms. Furthermore, heuristic algorithms are combined with simulation methods. The inventory modeling and solving of multi-item joint ordering mainly adopt probability, mathematical programming, numerical calculation method, and optimization method. According to the characteristics of demand and other information, a multi-item joint ordering strategy can be divided into two categories: deterministic type and random type. However, there are flaws, and the cost model considered more expenses and less service level; almost all inventory cost models take "average order satisfaction rate" as the standard to measure service quality while ignoring order response time. In addition, the optimization of multi-item joint ordering problem usually only considered the minimum inventory cost and order cost, but ignored the distribution cost, or it is considered as a constant, so the joint optimization of purchase, inventory, and delivery should be considered later.

This study has several contributions to the field of operation management in the cruise ship supply logistics. First, we put forward a new thought, which is entirely consistent with multiple sourcing according to the characteristics of cruise ship supplies, and also fill the research blank of joint ordering strategy of supplies in cruise operations. Second, an improved swarm intelligence algorithm, called fireworks algorithm with inertia weight (WFWA), is used to fix cruise ship supplies problem, which is an approach to solve an optimization model for joint purchase, inventory, and delivery under the supply chain environment.

\section{Problem Description and Modeling}

The main supply chain of the cruise company includes four main procurement processes: fuel purchasing, corporate purchasing, technical purchasing, and hotel purchasing. Fuel purchasing is responsible for acquiring and delivering fuel and other petroleum products such as lubricants to ship for its daily consumption. Corporate purchasing looks after most items required shore side as well as some corporate items used onboard such as office supplies and computers. Technical purchasing is the item mostly used by facility departments and marine departments such as engine parts and carpets. Finally, hotel purchasing is the department ensuring that foods and other consumable items required for hotel operations are in place; the procurement model of cruise ships is shown in Figure 1.

It needs a cruise distribution center as the supplies centralized hub for centralized purchasing, supervision, delivery, and settlement in the procurement model. The cruise distribution center could store all supplies with different order cycles and deliver to loading port through item checking, system receiving, and system shipping, thus avoiding loading port congestion caused by separate distribution from different suppliers. The purchasing model is useful to reduce distribution costs, integrate resources, and improve delivering efficiency. Therefore, it is of practical significance to study the optimization of multi-item joint ordering problem for cruise ship supply based on the cruise distribution center to reduce the cost of cruise logistics.

3.1. Problem Description. With the globalization of cruise ship supplies procurement, the cruise distribution center is required as the logistics base for multi-item and multisourcing in the cruise ship supply chain, which has storage function. The purchase and distribution adopt inventory coordination mode, and the optimization objective is cost minimization. The system is composed of a cruise distribution center and multiple ship suppliers with import and export business qualifications, either as partner suppliers or other warehouses around the logistics base. Many suppliers provide ship supplies with different lead times, which are concentrated in the cruise distribution center, and delivery to loading port after processing, as shown in Figure 2. Therefore, there exists a multi-item joint ordering problem of cruise ship supply in cruise operations. And how to determine the order cycle and order quantity of each item, and minimize ordering cost within the demand cycle, which is the multi-item joint ordering strategy of cruise ship supply.

The following assumptions are considered in our models:

(1) The initial inventory is 0 , replenishment is instantaneous, and there is no shortage. And the inventory capacity is $V$ (constant).

(2) There is a basic order cycle for cruise ship supplies. The order cycle of all supplies is an integer multiple of the basic order cycle, and the order cycle of one material is at least equal to the basic order cycle.

(3) The basic ordering cost of various supplies is the same, but the individual ordering costs vary. The 


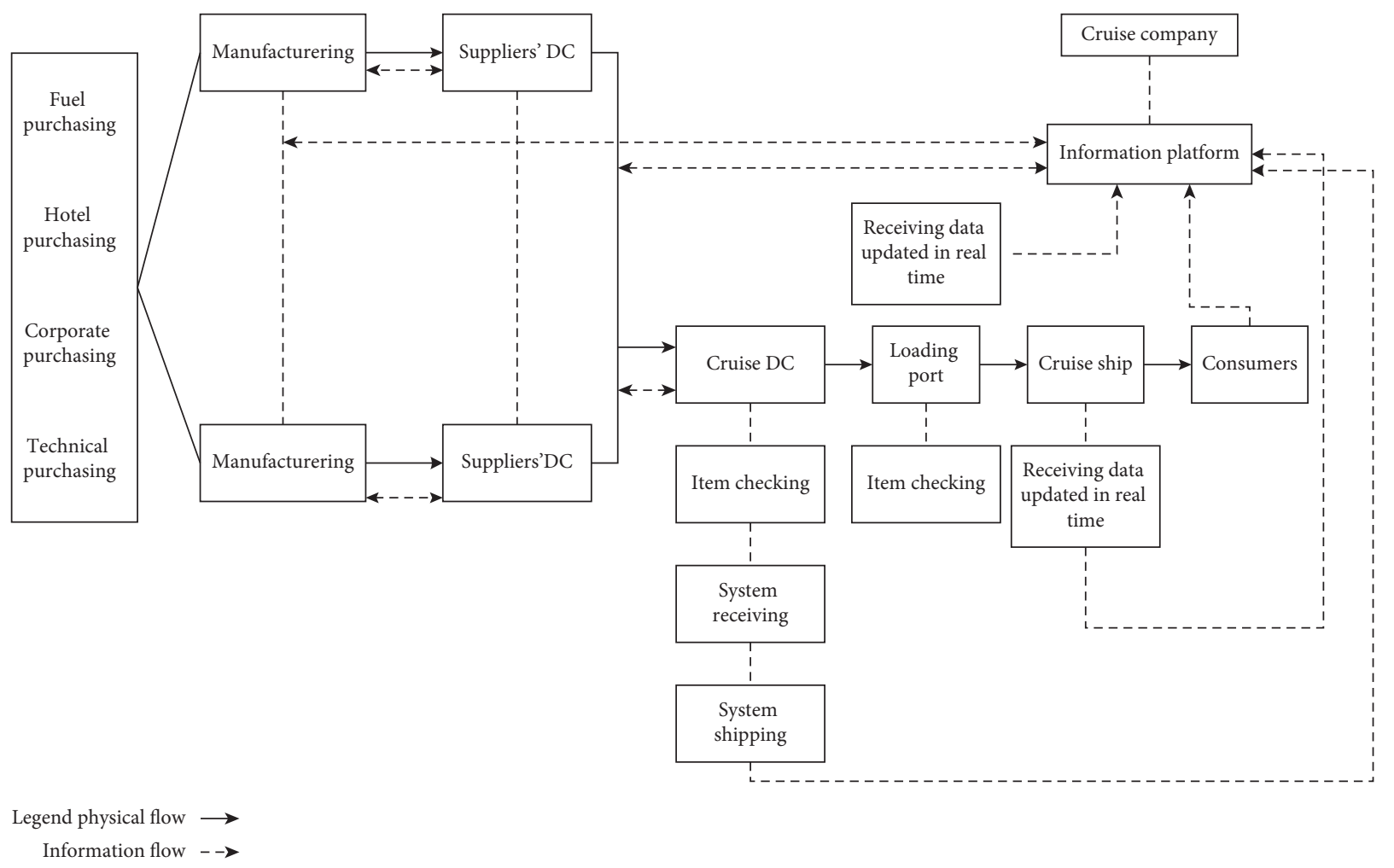

FIgURE 1: Cruise ship supplies purchasing model in supply chain environment.

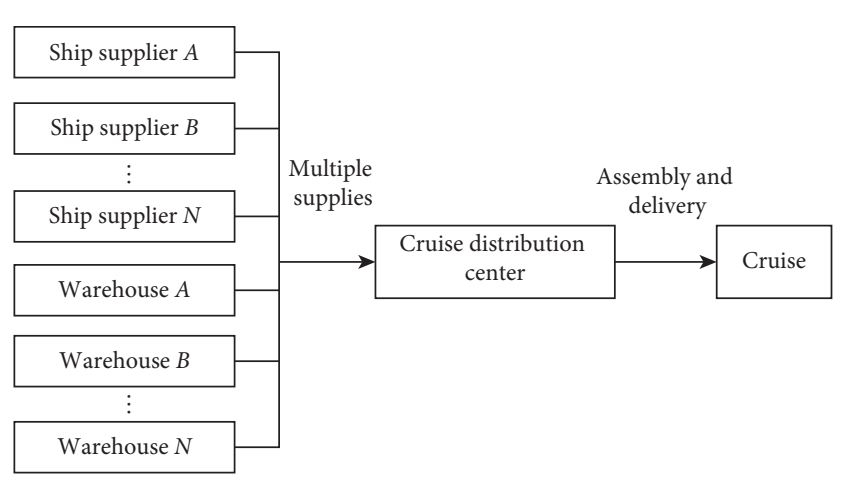

FIGURE 2: Joint ordering and distribution of multiple supplies based on a cruise distribution center.

subscription costs are related to the ordering times, and there is a basic subscription cost for each order.

(4) Based on the cruise distribution center, cruise companies send orders to suppliers on demand.

Definitions of parameters in our study are shown in Table 1.

3.2. Model Formulation. Supposing that the basic order cycle is $t$, the order cycle of material 1 is the same as material 2, which is the basic order cycle. Thus, material 1 and material 2 are divided into one group. Material 3 is twice the basic order cycle, that is, $2 t$, and material 3 is divided into one group, and so on. According to the above statement, each material order cycle $T_{i}$ is integer times the basic order cycle, which can formulated as follows:

$$
T_{i}=X_{i} * t
$$

Therefore, the order quantity of material $i$ is denoted as

$$
Q_{i}=R_{i} * T_{i}=R_{i} * X_{i} * t .
$$

Since the initial inventory of each material is 0 , the average inventory level of material $i$ is expressed as follows:

$$
\overline{I_{i}}=\frac{Q_{i}}{2}=\frac{R_{i} X_{i} t}{2} .
$$

Hence, the model of average total cost per unit time for multi-item joint ordering is defined as below:

$$
\min \operatorname{TC}\left(t, X_{1}, X_{2}, \ldots, X_{n}\right)=\frac{B+\sum_{i=1}^{n} b_{i} / X_{i}}{T}+\sum_{i=1}^{n} \frac{R_{i} X_{i} t H_{i}}{2},
$$

s.t. $\left\{\begin{array}{l}\sum_{i=1}^{n} R_{i} X_{i} t \leq V, \\ \min \left\{X_{i}, i=1,2, \cdots, n\right\}=1 .\end{array}\right.$

In the objective function (4), the first term indicates the total cost of multi-item joint ordering per unit time; the second term represents the inventory cost of various materials.

Formula (4) represents the constraints; the first constraint ensures that the total order quantity at the same time 
TABLE 1: Notations and definitions of parameters.

\begin{tabular}{lc}
\hline Notations & Definition \\
\hline$n$ & The number of types of cruise ship supplies \\
$R_{i}$ & Material $i, i=1,2, \ldots, n$ \\
$H_{i}$ & The demand rate of material $i$ \\
$B$ & Unit time inventory cost per unit of material $i$ in the cruise distribution center \\
$b_{i}$ & Basic ordering cost per order \\
$V$ & Individual ordering cost of material $i$ \\
$t$ & Inventory capacity of the cruise distribution center \\
$T_{i}$ & Basic order cycle (decision variable) \\
$X_{i}$ & The order cycle of material $i$ \\
$Q_{i}$ & The order cycle of material $i$ is $X_{i}$ times the basic order cycle (decision variable) \\
\hline
\end{tabular}

does not exceed the inventory capacity of the cruise distribution center; the second constraint indicates that the order cycle of at least one item is equal to the base order cycle of the cruise distribution center.

3.3. Model Solution. Firstly, $X_{i}$ is regarded as a constant in equation (4), and then we compute the first derivative of equation (4) with respect to $t$, as shown below:

$$
\frac{\mathrm{dTC}(t)}{\mathrm{d} t}=-\frac{B+\sum_{i=1}^{n} b_{i} / X_{i}}{t^{2}}+\sum_{i=1}^{n} \frac{R_{i} X_{i} H_{i}}{2} .
$$

As $\left(\partial^{2} \mathrm{TC}(t)\right) /\left(\partial^{2} t\right)=\left(B+\sum_{i=1}^{n} b_{i} / X_{i}\right) /\left(t^{3}\right)>0$, equation (5) can be set to zero, and then the basic order cycle can be expressed as follows:

$$
t^{*}\left(X_{1}, X_{2}, \ldots, X_{n}\right)=\sqrt{\frac{2\left(B+\sum_{i=1}^{n} b_{i} / X_{i}\right)}{\sum_{i=1}^{n} R_{i} X_{i} H_{i}}} .
$$

According to the constraints (4),

$$
\sum_{i=1}^{n} R_{i} X_{i} t \leq V
$$

Thus,

$$
t \leq \frac{V}{\sum_{i=1}^{n} R_{i} X_{i}}
$$

Suppose $t>V / \sum_{i=1}^{n} R_{i} X_{i}$, then $t^{*}=V / \sum_{i=1}^{n} R_{i} X_{i}$.

Next, we can get the formula simplified by substituting equation (6) into equation (4), which is denoted as

$$
\mathrm{TC}\left(X_{1}, X_{2}, \ldots, X_{n}\right)=\sqrt{2\left(B+\sum_{i=1}^{n} \frac{b_{i}}{X_{i}}\right) \sum_{i=1}^{n} R_{i} X_{i} H}
$$

Thus, the problem is to solve the optimal order cycle multiples for the various items, so as to minimize the average total cost of the system. According to equation (9), minimization of $\mathrm{TC}\left(X_{1}, X_{2}, \ldots, X_{n}\right)$ is equivalent to minimization of the following equation:

$$
F\left(X_{1}, X_{2}, \ldots, X_{n}\right)=\left(B+\sum_{i=1}^{n} \frac{b_{i}}{X_{i}}\right) \sum_{i=1}^{n} R_{i} X_{i} H_{i} .
$$

\section{Improved Swarm Intelligence Algorithm}

4.1. Fireworks Algorithm. Fireworks algorithm (FWA) is a novel swarm intelligence algorithm inspired by observing fireworks in the sky, which is proposed for global optimization of complex functions, in which two types of explosion (search) processes are employed, and the mechanisms for keeping diversity of sparks are also well designed [27]. The initialization of the fireworks algorithm is a process of generating fireworks randomly. Good explosion is in a small range with plenty of sparks, and the explosion operator is applied to the generated fireworks to generate new sparks. The core of FWA is explosion operator, including explosion intensity, explosion amplitude, and displacement operation.

4.1.1. Number of Sparks. The number of sparks generated by each firework $x_{i}$ is defined as below:

$$
S_{i}=m * \frac{Y_{\max }-f\left(x_{i}\right)+\varepsilon}{\sum_{i}^{N}\left(Y_{\max }-f\left(x_{i}\right)\right) Y_{\max }+\varepsilon},
$$

where $m$ is a parameter controlling the total number of sparks generated by the $N$ fireworks; $S_{i}$ is the number of sparks generated by firework $i ; Y_{\max }=\max \left(f\left(x_{i}\right)\right)$ $(i=1,2, \ldots, N)$ is the maximum (worst) value of the objective function among the $N$ fireworks; $f\left(x_{i}\right)$ is the fitness value of individual $x_{i}$; and $\varepsilon$, which denotes the smallest constant in the computer, is utilized to avoid zero-divisionerror.

4.1.2. Amplitude of Explosion. Amplitude of explosion for each firework $x_{i}$ is defined as follows.

In contrast to the design of sparks number, the amplitude of a good firework explosion is smaller than that of a bad one. The amplitude of explosion is defined as follows:

$$
A_{i}=\widehat{A} * \frac{f\left(x_{i}\right)-Y_{\min }+\varepsilon}{\sum_{i=1}^{N}\left(f\left(x_{i}\right)-Y_{\min }\right)+\varepsilon},
$$

where $\widehat{A}$ denotes the maximum explosion amplitude and $Y_{\text {min }}=\min \left(f\left(x_{i}\right)\right)(i=1,2, \ldots, N)$ is the minimum (best) value of the objective function among the $N$ fireworks. 
4.1.3. Generating Sparks. In explosion, sparks may undergo the effects of explosion from random $\Delta x_{i}^{k}$ directions (dimensions); we obtain the number of the affected directions randomly as follows:

$$
\Delta x_{i}^{k}=x_{i}^{k}+\operatorname{rand}\left(0, A_{i}\right),
$$

where $x_{i}^{k}$ is the dimensionality of location $x_{i}$ and $\operatorname{rand}\left(0, A_{i}\right)$ is a uniform distribution over $\left(0, A_{i}\right)$.

4.1.4. Spark Gaussian Explosion. Gaussian sparks are generated in a Gaussian explosion process, and Gaussian sparks conducts search in a local space around a firework which can be written as

$$
x_{i}^{k}=x_{i}^{k} G
$$

where $G$ is a random number of Gaussian distributions with mean 1 and variance 1 , that is, $G \sim N(1,1)$.

4.1.5. Selection of Locations. The selection probability of a location $x_{i}$ is denoted as follows:

$$
p\left(x_{i}\right)=\frac{R\left(x_{i}\right)}{\sum_{j \in K} R\left(x_{j}\right)},
$$

where

$$
R\left(x_{i}\right)=\sum_{j \in K} d\left(x_{i}, x_{j}\right)=\sum_{j \in K}\left\|x_{i}-x_{j}\right\| .
$$

In equations (15) and (16), $R\left(x_{i}\right)$ is the sum of the distances between $x_{i}$ and other individuals; $j \in K$ means that the first location $j$ belongs to set $K$, which is the set of sparks generated by explosion operator and Gauss mutation; $p\left(x_{i}\right)$ is the probability that each individual chooses to use roulette gamblers; and $d\left(x_{i}, x_{j}\right)$ is the Euclidean distance between any two individuals $x_{i}$ and $x_{j}$.

4.2. Improved Fireworks Algorithm. The fireworks algorithm with inertia weight (WFWA) is a new algorithm based on the FWA, which adds inertia weight to the spark position update formula as shown in equations (17) and (18) and improves the explosion radius by inertia weight [28]. A fireworks algorithm with nonlinear inertia weight $w(t)$ is introduced to accelerate the convergence speed and improve the performance of the algorithm, in which the inertia weight varies with the optimization ability. The larger the value of inertia weight, the stronger the global optimization ability; when it is small, the algorithm is local optimization. Compared with PSO, GA, FOA, and other swarm intelligence algorithms, WFWA has better convergence, global optimization, and search ability [28-35]. Therefore, WFWA is a good choice to solve the ordering optimization problem of cruise ship supply to the integrated purchase, delivery, and inventory in the supply chain environment.

$$
\begin{array}{r}
\widehat{x}_{j}^{k}=w \widetilde{x}_{j}^{k}+A_{j} \cdot \operatorname{rand}(-1,1)\left(j=1,2, \ldots, \widehat{s}_{i}\right), \\
w=\left(\frac{1}{2}\right)^{t},
\end{array}
$$

where $t$ represents the number of evaluations and $w$ decreases with the number of iterations.

The flowchart of WFWA is shown in Figure 3.

\section{Experimental Testing and Analyses}

5.1. Experimental Data. We select the data of a cruise company for empirical test and analysis, which wants to purchase a batch of supplies from all over the world, including ten categories with different ordering cycles. The ship supplies require delivery from different suppliers (other warehouses around) to a cruise distribution center, in which they would be assembled and delivered to the cruise ships because separate distribution will inevitably increase additional costs and cause congestion at the loading port. The relevant data of cruise ship supplies purchasing are shown in Table 2, and the basic order cost $B$ is 50 yuan; the storage capacity of cruise distribution center is 600 pieces.

5.2. Simulation Results and Analysis. In this section, in order to verify the effectiveness of the improved swarm intelligence algorithm (WFWA) in solving the procurement optimization problem, the simulation results of WFWA are compared with the fireworks algorithm (FWA), genetic algorithm (GA), and particle swarm optimization (PSO). In the environment of MATLAB, the data in Table 2 are taken as an example for simulation experiment. The number of iterations is 500 times, and each algorithm runs 20 times independently. The parameters of WFWA and FWA are as follows: population size $N$ is 5 , constant $m$ is 50 , explosion number is 6 , explosion radius is 40 , explosion limiting factor $a=0.04$ and $b=0.8$, Gauss variation spark number is 5 , and function variable dimension $D$ is 10 . The particle number is 10 , and gama parameter is 0.95 for PSO. And the parameters of GA are as follows: the population size is 10, the crossover probability is 0.75 , and the mutation probability is 0.75 .

The simulation results of the four swarm intelligence algorithms are shown in Figure 4, which indicates that WFWA has the fastest convergence rate and the highest efficiency in the optimum results. Compared with WFWA, FWA and PSO are slower, and GA is the slowest. According to the analysis of simulation results compared with FWA, PSO, and GA, Table 3 lists the testing results for optimal value, worst value, average optimal value, and standard deviation, which evaluate the performance and stability of the algorithms. It can be concluded from Table 3 that the proposed WFWA performs better than FWA, PSO, and GA in optimal solution and average optimal solution and has better robustness. Compared with the other three algorithms, WFWA has better convergence rate and accuracy and can better search for the global optimal solution. 


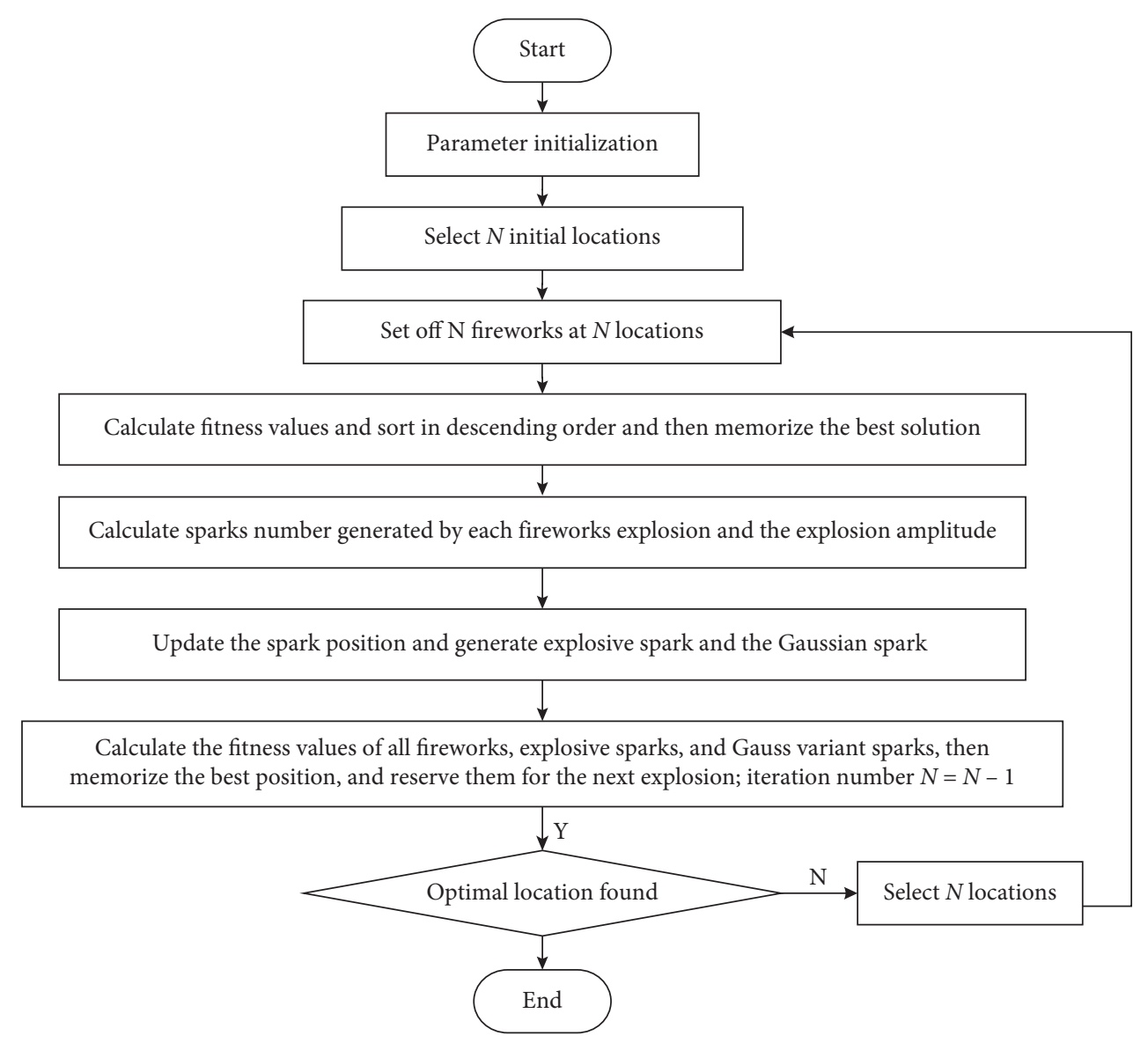

Figure 3: The flowchart of WFWA.

TABLe 2: Cruise ship supplies purchase list details.

\begin{tabular}{lccc}
\hline Supplies & $\begin{array}{c}\text { Individual } \\
\text { ordering cost } b_{i} \\
\text { (yuan/time) }\end{array}$ & $\begin{array}{c}\text { Demand rate } R_{i} \\
\text { (parts/quarters) }\end{array}$ & $\begin{array}{c}\text { Inventory Cost } \\
H_{i} \text { (yuan/piece) }\end{array}$ \\
\hline 1 & 80 & 1700 & 8 \\
2 & 100 & 1200 & 10 \\
3 & 50 & 1500 & 10 \\
4 & 150 & 1000 & 17 \\
5 & 200 & 400 & 15 \\
6 & 180 & 1200 & 26 \\
7 & 280 & 200 & 5 \\
8 & 220 & 500 & 35 \\
9 & 250 & 800 & 10 \\
10 & 400 & 600 & 14 \\
\hline
\end{tabular}

WFWA is used to calculate the order cycle of each item of cruise ship supplies; the results are shown in Table 4 .

According to the constraint $\sum_{i=1}^{n} R_{i} X_{i} t \leq V$, the basic order cycle can be calculated as the follows:

$$
t>\frac{V}{\sum_{i=1}^{n} R_{i} X_{i}}=0.0283 \text {. }
$$

As a result, $T^{*}$ is 0.0283 quarter, namely, 3 days.

It can be seen from Table 4 that after the adjustment of $X_{i}$, the order cycle of material 3 is 3 days; the order cycle of materials $1,4,6$, and 8 is 6 days; the order cycle of material 2

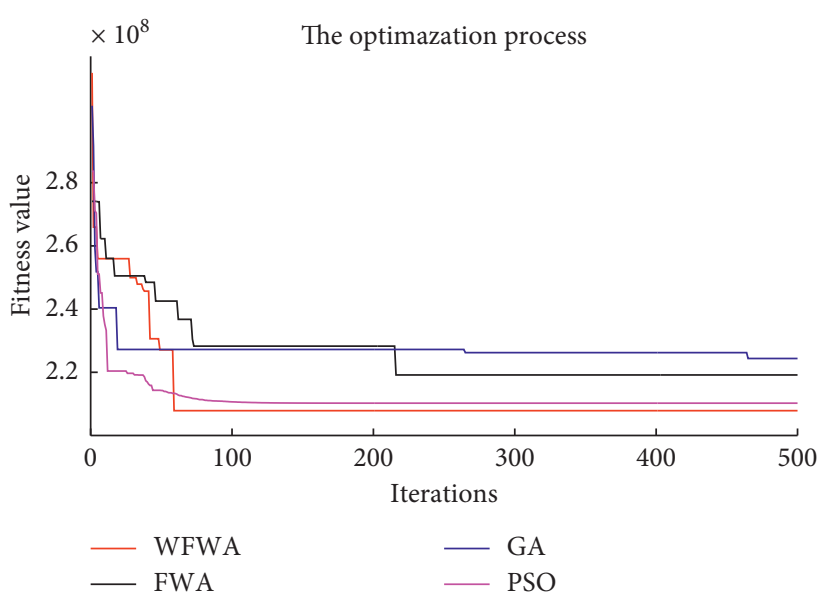

FIgURE 4: Simulation optimization process of different swarm intelligence algorithms.

is 9 days; the order cycle of material 9 is 12 days; the order cycle of materials 5 and 7 is 15 days; and the order cycle of material 10 is 24 days.

Therefore, the order quantity of each kind of cruise ship supplies can be calculated according to equation (2), and the results are shown in Table 5.

Finally, the total procurement cost is as follows: 
TABLE 3: The results of simulation experiment.

\begin{tabular}{lcccc}
\hline Algorithms & WFWA & FWA & GA & PSO \\
\hline Optimal solution & $2.079 e+08$ & $2.192 e+08$ & $2.244 e+08$ & $2.155 e+08$ \\
Worst value & $3.148 e+08$ & $2.741 e+08$ & $3.044 e+08$ & $3.232 e+08$ \\
Average optimal solution & $2.125 e+08$ & $2.261 e+08$ & $2.274 e+08$ & $2.178 e+08$ \\
Standard deviation & $1.372 e+07$ & $1.105 e+07$ & $5.498 e+06$ & $8.951 e+06$ \\
\hline
\end{tabular}

TABLE 4: Calculation result of cruise ship supplies order cycle.

\begin{tabular}{lcccccccccc}
\hline & $X_{1}$ & $X_{2}$ & $X_{3}$ & $X_{4}$ & $X_{5}$ & $X_{6}$ & $X_{7}$ & $X_{8}$ & $X_{9}$ & $X_{10}$ \\
\hline Calculation & 2.2806 & 3.2968 & 1.3011 & 2.4346 & 4.8441 & 2.2445 & 5.2910 & 2.4576 & 3.6690 & 8.4158 \\
Modulation & 2 & 3 & 1 & 2 & 5 & 2 & 5 & 2 & 4 & 8 \\
\hline
\end{tabular}

TABle 5: Calculation result of cruise material order quantity.

\begin{tabular}{lcccccccccc}
\hline & $Q_{1}$ & $Q_{2}$ & $Q_{3}$ & $Q_{4}$ & $Q_{5}$ & $Q_{6}$ & $Q_{7}$ & $Q_{8}$ & $Q_{9}$ & $Q_{10}$ \\
\hline Order quantity & 96 & 102 & 42 & 57 & 57 & 68 & 28 & 28 & 91 & 136 \\
\hline
\end{tabular}

$$
\mathrm{TC}=\frac{B+\sum_{i=1}^{n} b_{i} / X_{i}}{T^{*}}+\sum_{i=1}^{n} \frac{Q_{i} H_{i}}{2}=28077 \text { Yuan }
$$

\section{Conclusions}

With the globalization of cruise ship supplies purchasing, multisourcing brings our attention to multi-item joint ordering in cruise ship supply logistic; this paper considers the optimization objective of inventory collaborative operation in purchase and delivery from the perspective of supply chain and establishes a model of multi-item joint ordering based on a cruise distribution center to minimize the logistics procurement cost for cruise ship supply. And most swarm intelligence algorithms have slow convergence rate and are easily trapped in local optimum; an improved intelligence algorithm WFWA is proposed to solve it. The comparison with GA, PSO, and FWA verifies the effectivity and efficiency of WFWA. Basic order cost and inventory capacity are two key initial values in the model, which are closely related to the order cycle. And as the basic order cost value decreases, the gap between the order cycle of each material and the basic order cycle increases, and the total cost decreases. Meanwhile, the advantage of multi-item joint ordering will be more visible. At the same time, with the decrease of inventory capacity, the basic order cycle will decrease, and the order cycle of each material will also reduce, causing the cost to rise. However, excessive inventory capacity would lead to waste of warehouse resources and increased storage cost. This model considers purchase cost, inventory cost, and delivery cost, which has practical significance for the optimization of cruise ship supply logistics in China. Nevertheless, because of large quantity, high efficiency, and low unit value of the cruise ship supply at the cruise home port, ship suppliers should have sufficient inventory to response to the orders from cruise company, which would cause corresponding inventory costs and other logistics costs for ship suppliers. For the ship suppliers of a commodity supply interruption, the shortage cost can be immeasurable in a certain extent for cruise company. Hence, the optimization problem of interruption risk is also worthy of study in the purchasing process of cruise supply chain.

\section{Data Availability}

The data used to support the findings of this study are included in the article.

\section{Conflicts of Interest}

The authors declare that there are no conflicts of interest regarding the publication of this paper.

\section{Acknowledgments}

This research was supported by the National Natural Science Foundation of China (grant no. 51279153).

\section{References}

[1] D. Vukonic, D. Bielic, and A. Russo, "Organizational factors in management of "Mega Cruise Ships" from crowd management control aspect," Scientific Journal of Maritime Research, vol. 30, no. 1, pp. 58-66, 2016.

[2] J. W. Jones, "Accounting practices in ship chandlery," Management Accounting, vol. 55, no. 2, p. 28, 1973.

[3] S. Véronneau and J. Roy, "Global service supply chain: an empirical study of current practices and challenges of a cruise line corporation," Tourism Management, vol. 30, no. 1, pp. 129-139, 2009.

[4] G. K. Vaggelas and I. N. Lagoudis, "Analysing the supply chain strategy of the cruise industry-the case of a small cruise company," in Proceedings of the International Association of Maritime Economists (IAME 2010), Lisbon, Portugal, July 2010.

[5] S. Véronneau and Y. Cimon, "Maintaining robust decision capabilities: an integrative human-systems approach," Decision Support Systems, vol. 43, no. 1, pp. 127-140, 2007.

[6] P. Lois, J. Wang, A. Wall, and T. Ruxton, "Formal safety assessment of cruise ships," Tourism Management, vol. 25, no. 1, pp. 93-109, 2004.

[7] C. X. Fu and J. M. Shou, "The global cruise material supply chain research," Jiangsu Commercial Forum, vol. 6, pp. 21-24, 2015.

[8] H. J. Liu, "Discussion on how to formulate the material supply chain management system in cruise industry operation," 
Logistics Engineering and Management, vol. 39, no. 12, pp. 55-58, 2017.

[9] X. Y. Yin, "Experience of international cruise material distribution in home port," Shipping Management, vol. 7, pp. 25-28, 2013.

[10] J. Zheng, H. Zhang, L. Yin et al., "A voyage with minimal fuel consumption for cruise ships," Journal of Cleaner Production, vol. 215, pp. 144-153, 2019.

[11] J. L. Balintfy, "On a basic class of multi-item inventory problems," Management Science, vol. 10, no. 2, pp. 287-297, 1964.

[12] S. K. Goyal, "Determination of economic packaging frequency for items jointly replenished," Management Science, vol. 20, no. 2, pp. 232-235, 1973.

[13] E. A. Sivler, "A simple method of determining order quantities in joint replenishments under deterministic demand," Management Science, vol. 22, no. 12, pp. 1351-1361, 1976.

[14] H. Pirkul and O. A. Aras, "Capacitated multiple item ordering problem with quantity discounts," IIE Transactions, vol. 17, no. 3, pp. 206-211, 1985.

[15] C. J. Xu and E. Xu, "A multi-item ordering tactics at regular intervals in reverse logistics," Logistics Technology, vol. 5, pp. 28-29, 2006.

[16] L. Zhu, J. T. Zhang, and J. X. You, "Study on supply chain aggregation effects based on variety of products or customers ordering strategy," Journal of Tongji University: Natural Science, vol. 37, no. 1, pp. 134-138, 2009.

[17] X. W. Wen and Q. L. Da, "Ordering policy and empirical study of multi-product in a supply chain," Journal of Industrial Engineering and Engineering Management, vol. 21, no. 1, pp. 56-60, 2007.

[18] J. L. Zhang, L. Wang, T. Chen, and Y. R. Zeng, "Coordinated replenishment problem of rarely used spare parts based on continue production," Chinese Journal of Management Science, vol. 12, no. 5, pp. 58-62, 2004.

[19] J. R. Zhang, Y. L. Yu, Y. L. Zhang, and C. C. Qu, "Joint order model of multi-items maintenance spare parts based on periodic policy," Fire Control \& Command Control, vol. 37, no. 9, pp. 112-116, 2012.

[20] Z. M. Guan and H. Wu, "Optimized model for order quantity allocation of multi-product purchase with fuzzy demand," Journal of Northeastern University: Natural Science, vol. 33, no. 8, pp. 1198-1201, 2012.

[21] N. K. Verma, A. Chakraborty, and A. K. Chatterjee, "Joint replenishment of multi retailer with variable replenishment cycle under VMI," European Journal of Operational Research, vol. 233 , no. 3 , pp. $787-789,2014$

[22] I. K. Moon, S. K. Goyal, and B. C. Cha, "The joint replenishment problem involving multiple suppliers offering quantity discounts," International Journal of Systems Science, vol. 39, no. 6, pp. 629-637, 2008.

[23] L. Cui, L. Wang, J. Deng, and J. Zhang, "Intelligent algorithms for a new joint replenishment and synthetical delivery problem in a warehouse centralized supply chain," Knowledge-Based Systems, vol. 90, pp. 185-198, 2015.

[24] Y.-C. Tsao and W.-G. Teng, "Heuristics for the joint multiitem replenishment problem under trade credits," IMA Journal of Management Mathematics, vol. 24, no. 1, pp. 63-77, 2013.

[25] P. Ongkunaruk, M. I. M. Wahab, and Y. Chen, "A genetic algorithm for a joint replenishment problem with resource and shipment constraints and defective items," International Journal of Production Economics, vol. 175, pp. 142-152, 2016.
[26] B. Marcello, C. Davide, and G. Mose, "An extension of the stochastic Joint-Replenishment Problem under the class of cyclic policies," Operations Research Letters, vol. 44, no. 2, pp. 278-284, 2016.

[27] Y. Tan, Fireworks Algorithm: A Novel Swarm Intelligence Optimization Method, Springer, Berlin, Germany, 2015.

[28] Y. Tan and Y. Zhu, "Fireworks algorithm for optimization," Lecture Notes in Computer Science, vol. 6145, pp. 355-364, 2010.

[29] Y. F. Shang, X. Y. Liu, and M. N. Jia, "Fireworks algorithm with inertia weight," Journal of Inner Mongolia University of Technology, vol. 35, no. 3, pp. 168-177, 2016.

[30] W. Guo, J. Li, G. Chen, Y. Niu, and C. Chen, "A PSO-optimized real-time fault-tolerant task allocation algorithm in wireless sensor networks," IEEE Transactions on Parallel and Distributed Systems, vol. 26, no. 12, pp. 3236-3249, 2015.

[31] W. Guo, G. Liu, G. Chen, and S. Peng, "A hybrid multiobjective PSO algorithm with local search strategy for VLSI partitioning," Frontiers of Computer Science, vol. 8, no. 2, pp. 203-216, 2014.

[32] G. Liu, W. Guo, Y. Niu, G. Chen, and X. Huang, "A PSObased timing-driven Octilinear Steiner tree algorithm for VLSI routing considering bend reduction," Soft Computing, vol. 19, no. 5, pp. 1153-1169, 2015.

[33] L. Guo, M. Li, and D. Xu, "Efficient approximation algorithms for maximum coverage with group budget constraints," Theoretical Computer Science, vol. 788, pp. 53-65, 2019.

[34] G. Liu, W. Guo, R. Li, Y. Niu, and G. Chen, "XGRouter: highquality global router in $\mathrm{X}$-architecture with particle swarm optimization," Frontiers of Computer Science, vol. 9, no. 4, pp. 576-594, 2015.

[35] G. G. Liu, X. Huang, W. Z. Guo, Y. Z. Niu, and G. L. Chen, "Multilayer obstacle-avoiding X-architecture steiner minimal tree construction based on particle swarm optimization," IEEE Transactions on Cybernetics, vol. 45, no. 5, pp. 989-1002, 2015. 